created by the outrushing air which dragged microorganisms from the surrounding air onto the plate. In order to eliminate this undesirable effect we tried fastening funnels of various sizes by means of a rubber attachment to the cock. We found that a funnel whose circumference was exactly that of our dish gave us the best results so this method has been adopted for taking air samples rapidly throughout the plant.

LABORATORY OF ThE WM. J. LEMP BREWING COMPANY Sr. Lovis

\section{AN ETHER RECOVERY TUBE}

By J. M. PICEEL

Recejved December 17, 1914

In fat extractions with the Knorr flask, it is.customary to recover the ether by removing the extraction tube and putting in its place a test tube. The accompanying sketch shows an arrangement by which this exchange of tubes and attendant loss of time and ether are obviated. During the extraction the ether drops from the point $C$ into the funnel $d$, which con-

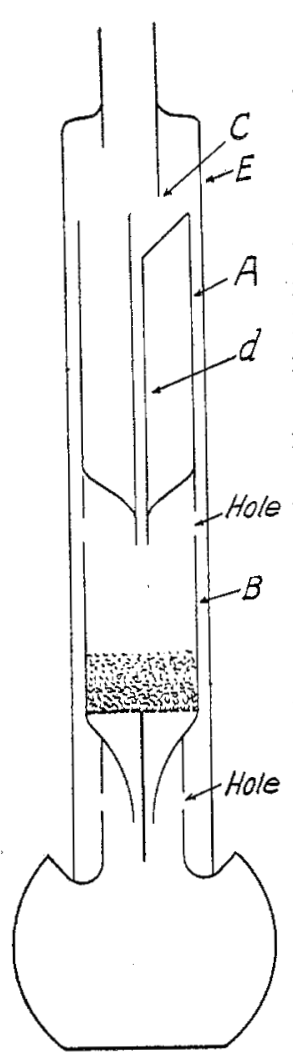
veys it into the extraction tube B. When the extraction is finished, the other side of the tube $A$ is brought under the point $C$; this is accomplished without interrupting the distillation, by merely turning the Knorr flask. The funnel, which is made of either glass or metal, has the peculiarity of being a half funnel, covering but one-half the mouth of the tube $A$ to which it is fused at its lower end only.

The extraction tube $B$ need not be over 4 or $5 \mathrm{~cm}$. long to accommodate an ordinary charge ( $2 \mathrm{~g}$. substance) and instead of two holes near its top for the circulation of vapor, two $V$-shaped notches filed in its edge are equaliy efficient. The inside diameter of the standard hole cylinder $\mathrm{E}$ is about $3.2 \mathrm{~cm}$. (1.25 inches); the outside diameter of $\mathrm{A}$ should therefore be not less than 2.7 $\mathrm{cm}$. ( $\mathrm{I}^{1 / 8} \mathrm{~s}$ inches). The length of $\mathrm{A}$ should be the greatest possible without touching the point $\mathrm{C}$ when it is revolved.

The inside diameter of the necks of the Knorr flasks need not, and should not, be less than 22 or $23 \mathrm{~mm}$. In that case, the extraction tube can be dispensed with, and in its stead a standard paper thimble, I9 mm. diameter, used. The thimble is placed inside the neck of the Knorr, its lower end reaching down to within I cm. of the surface of the ether; it Inay be conveniently supported in that position by a small copper wire permanently wound around it, ends of the wire on opposite sides resting on top of the neck of the Knorr. The space gained in the cylinder $E$ by thus sinking the extraction thimble into the Knorr, makes it possible to give added length and capacity to the recovery tube A. Moreover, the extraction takes place in ether vapor, at practically the boiling point of ether, and it is claimed that an extraction in that case is complete in about 4 hours instead of the usual sixteen.

NORTF Carolina DEpartment of Agriculture, RALEYGH

\section{A CONVENIENT FORM OF WEIGHING PIPETTE}

By A. T. MERTES

Received January 27, 1915

For conveniently and accurately weighing out quantities of glycerine such as are used in the determination of glycerol by the acetine method, the writer devised the form of apparatus shown. It is convenient and useful for weighing out oils for the determination of the Iodine Number, especially those oils having a high iodine absorption, and which require an accurate weight. For Koett. storfer and Reichert-Meissl Numbers, the pipette may be calibrated so as to assist in delivery of the proper amount of fat or oil.

The pipette can be made by any one having a little skill in glass working. The writer uses an old ro cc. pipette and fuses a glass stopcock to one end. The other end of the bulb is drawn out and bent into a hook as shown in the sketch.

In order to fill the pipette, a rubber tube is attached to the upper end and the desired amount of the fat or other substance sucked up into it. The stopeock is then closed, the delivery tube wiped of and the pipette suspended by the hook from a balance and weighed.

6537 Woodlawn Aveave, Chicago

\section{A FILTER-PIPETTE FOR ETHER}

BY J. M. PICKEL

Received December 17, 1914

The accompanying illustration shows a device for filtering ether without waste and simultaneously de-

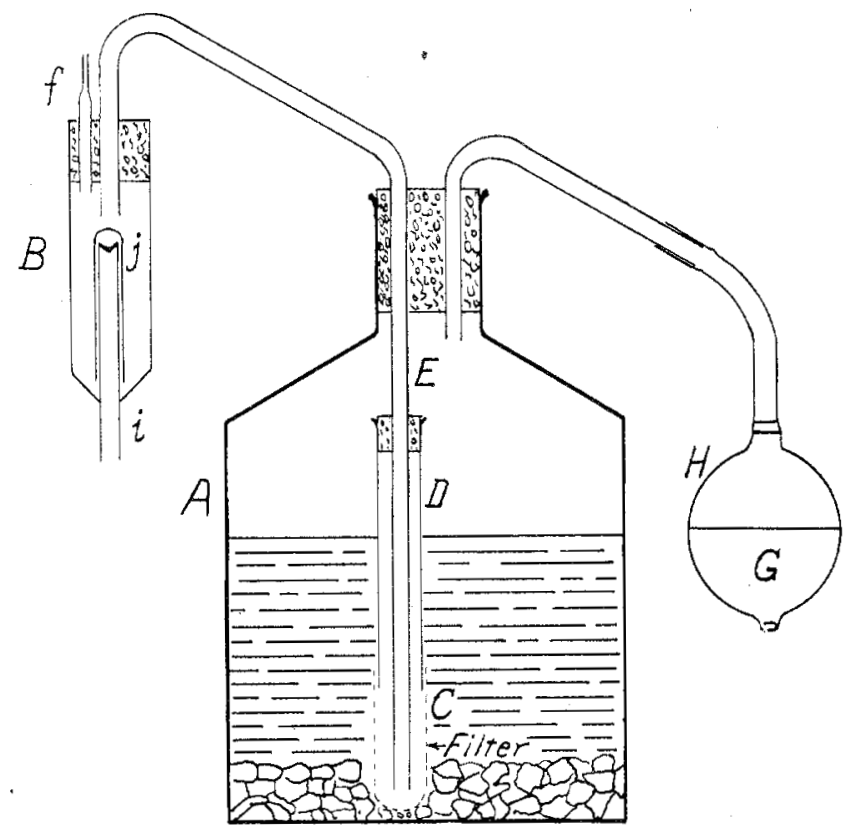

livering it in requisite measure into fat extraction flasks. 
The ether is forced by the rubber bulb $G$, through the filter $C$, up the tube $E$, into the pipette $B$, which delivers it into the flasks. The bulb has only one valve; the small hole $\mathrm{H}$ in its side is to be closed by the thumb during compression and to be uncovered the instant the ether begins to overflow into the tube $i$.

The filter is an ordinary paper thimble for fat extraction, fitting snug and tight over the tube D, which is attached by fusion or by cork to the tube $E$. A thimble Ig $\mathrm{mm}$. in diameter and extending 2 or 3 $\mathrm{cm}$. below the end of the tube $\mathrm{D}$ furnishes ample filtering surface. A few wrappings of thread will make it fast to $D$.

The pipette is what is known as the engineers' siphon. It consists of the cylinder $B$, inside diameter about $27 \mathrm{~mm}$. and length ro or $15 \mathrm{~cm}$., as may be required; the fused-in tube $i$, about 3 or $4 \mathrm{~mm}$. inside diameter and about $57 \mathrm{~mm}$. Iong above its union with the cylinder; the cap $j$, about $8 \mathrm{~mm}$. inside diameter by about $53 \mathrm{~mm}$. long; the vent tube $f$. A pipette of these dimensions will deliver about $25 \mathrm{cc}$, ample in the Raleigh climate for an ordinary extraction (2 g. of substance), but it is well to give the pipette greater capacity than that and reduce it to any desired volume by placing inside the cylinder glass beads, or better, glass rods. The cap $j$ is supported on the end of $i$, which end should be ground slanting on opposite sides, V-shaped, permitting the passage of the liquid.

This method of filtering ether was devised and used by the writer six or eight years ago but it had fallen into disuse until the past winter since which time he has again had occasion to make numerous fat extractions.

North Carolina Department of Agriculture RALEIGH

\section{ADDRESSES}

\section{THE DYESTUFF SITUATION AND ITS LESSON 1}

By ARTHur D. LITTLE

Manufacturers of American flags are in no immediate danger of having to rely upon Cape Cod cranberries for their red or California skies for their blue. Nor is it probable that our textile manufacturers generally will be forced to adopt the suggestion that we utilize our native rainbows to supply the tinctorial requirements of their industry. Six months ago the situation was different. You could have sold rainbows by the foot. The people generally and even the consumers of dyestuffs awoke at the first declaration of war to the long patent fact that the industries of these United States are dependent upon Germany for their supplies of coloring matters, synthetic drugs and many other highly necessary products derived from coal tar. A situation which had been eminently satisfactory to consumers for many years suddenly appeared humiliating and intolerable when the embargo first threatened to cut off supplies. There were insistent demands for the immediate inauguration of an American coal-tar color industry to relieve the situation and render impossible its recurrence. It was to be established by changing the tariff and the patent laws and letting somebody else find the money. Government ownership of dyestuff plants was not considered serionsly because there were no German plants interned.

With the lifting of the embargo and the resumption of shipments by way of Rotterdam most of the humiliation disappeared while now there is even a growing disinclination upon the part of textile manufacturers to let the other fellow find the moneyand make those essential changes in the tariff. The situation nevertheless remains one to cause concern and involves many factors which are worthy of your serious consideration.

All the world knows that during the last fifty years a sweeping revolution has been effected in the art of dyeing. The vegetable dyes like logwood, fustic, sumac, madder, indigo and many others, the few animal dyes like cochineal and the relatively crude mineral pigments have all been displaced completely or in greater part by the products of synthetic chemistry after a record of tinctorial service extending back to the days of Genesis. The coal-tar color industry, which began in 1856 with the discovery of mauve by an English boy of eighteen, known later as Sir William Henry Perkin, soon took root in Germany where it has attained its present great development and delicately adjusted organization mainly through the genius of a few and the plodding

1 Address before the United States Chamber of Commerce, Washington, February 5, 1915. industry of many German chemists, the far-sighted courage of German financiers and the technical and business sagacity of German managers. It is in a very real sense a created industry brought into being by the reaction of intellect upon the black chaos of coal tar. It is peculiarly a German industry and its products for the most part may justly and proudly bear the legend, "Made in Germany."

Contrary to popular belief the products of this industry have displaced the old vegetable dyes because they are better, brighter, faster, easier of application, cheaper and incomparably wider in color range.

With our textile and paper mills, paint and varnish manufacturers, makers of printing inks, and many minor industries thus definitely committed to the use of coal-tar dyes it is not surprising that the sudden prospect of a dyestuff famine should have occasioned grave concern. At the outbreak of the war the textile mills were generally credited with having not more than five months' supply on hand. The other industries concerned were probably less fortunate. For a time the German embargo on dyestuffs prevented shipments, and stocks were rapidly depleted. Through the persistent, earnest and capable efforts of American representatives of the German manufacturers shipments have been resumed under some restrictions but with reasonable regularity. The German plants are running at about 60 per cent capacity and distribution of their product is regulated by the government through the Society of Dyestuff Manufacturers. The basis of allotment is said to be 75 per cent of the I9I 3 consumption distributed over monthly shipments which must go forward in American boats. There is little doubt that to prevent reshipment to the allies it is the German policy to keep our own mills in a chronic state of dyestuff hunger. As a result many mills are now running from hand to mouth, others claim to be provided for three months and a few for a somewhat longer period on certain lines of colors.

As a result of the close interdependence of the coal-tar dyes and coal-tar explosives industries there has been a practically complete cessation of receipts of such dyes and developers as require for their manufacture nitric acid or raw materials derived from coal tar and available for the production of explosives. Such materials for example are toluol and carbolic acid.

The acid blues and acid blacks largely used in dyeing woolens are already scarce as are also most yellows and oranges and a wide variety of blues and greens. Paranitraniline, used in connection with pigment red in poster work, is practically out of 